Dr Branko Đedović,

pukovnik, dipl. inž

dr Branislav Jakić,

pukovnik, dipl. inž.

Ministarstvo odbrane SCG,

Sektor za materijalne resurse,

Beograd

\section{PRILOG KVALITETU U ODBRAMBENIM TEHNOLOGIJAMA SA ASPEKTA LOGISTIČKIH POTREBA*}

Rezime:

Nove krize i izazovi kao oblici reagovanja nametnuli su potrebu da ekonomski $i$ vojno jake, industrijski i tehnološki razvijene zemlje jačaju faktor kvaliteta u odbrambenim tehnologijama u funkciji demonstracije vojne sile i tehnološke moći. Odbrambene tehnologije i savremene strategije su u komplementarnom odnosu i uzročno-posledičnoj vezi. Brze tehnološke promene neizbežno zahtevaju projektovanje i programiranje ključnih parametara kvaliteta, kako bi sinergijski efekat dejstva tehnike i taktike imali optimalno postizanje cilja. Operativni izraz osnovnih činilaca kvaliteta ogleda se u logističkim postavkama podrške borbenim dejstvima i kriterijumima efikasnosti i gotovosti za upotrebu. Sistem menadžmenta kvaliteta u odbrambenim tehnologijama, u kontekstu logističkih potreba, omogućuje kvalitetan opis $i$ pouzdanu predikciju u oblasti realizacije zadataka.

Ključne reči: kvalitet, odbrambene tehnologije, logistička podrška, sistem menadžmenta u oblasti kvaliteta.

\title{
CONTRIBUTION TO THE QUALITY FACTOR IN DEFENCE TECHNOLOGIES FROM THE STANDPOINT OF LOGISTIC NEEDS
}

\section{Summary:}

Economically and military strong industrial and technologically developed countries face rising crises and challenges as reactions which impose the need of strengthening the quality factor in defence technologies as a demonstration of military force and technological supremacy. Being in the relation of cause and effect, defence technologies and modern strategies complement each other. Fast technological changes require design and programming of quality key parameters in order to achieve an optimum goal through the synergy of technology and tactics. The operational expression of basic quality parameters reflects in the logistic support prerequisites for combat actions as well as for efficiency and combat readiness criteria. The quality management system in defence technologies enables a high-quality description and a reliable prediction of mission realization.

Key words: quality, defence technologies, logistic support, quality management system.

\section{Uvod}

Značaj odbrambenih tehnologija za privredni i socijalni razvoj i konkurentnost proizvoda, usluga, organizacija, sektora i celokupne nacionalne ekonomije, nameće potrebu mudrog i efikasnog

Rad je saopšten na Nacionalnoj konvenciji o kvalitetu 2004, održanoj od 20. do 24. juna u Beogradu. upravljanja tehnološkim razvojem u svim područjima i na svim nivoima.

Najaktuelniji problemi proizvodnje se, istorijski gledano, premeštaju sa sredstava za rad preko resursa na tehnologije procesa obrade resursa (na znanje). Zbog jačanja konkurentnosti kreativnost se usmerava u nove oblasti. Metodama za optimalno angažovanje znanja i raspode- 
lu ograničenih materijalnih resursa privrednog potencijala stvaraju se pretpostavke za poboljšanje kvaliteta.

Tehnološka definicija kvaliteta, koja proizilazi iz suštine savremenog pristupa upravljanju privrednim razvojem, ukazuje na njegovu svrhu i ciljeve. Osnovne odrednice takvog gledišta kvaliteta su: da služi upravljanju kao pokazatelj valjanosti upravljačkih rešenja; da omogući preduzimanje pravovremenih korektivnih mera; da omogući spoznaju elemenata i procesa poboljšanja upravljanja.

\section{Kvalitet u odbrambenim tehnologijama}

Nove sistemske postavke obezbeđenja kvaliteta i nove tehnološko-tehničke mogućnosti u armijama ekonomski i tehnološki razvijenih zemalja, malim zemljama sa odbrambenom doktrinom nametnule su potrebu iznalaženja sopstvenih modela tehničke modernizacije i uspostavljanja sistema menadžmenta kvalitetom u razvoju i proizvodnji sredstava naoružanja i vojne opreme (NVO).

Veoma intenzivan razvoj odbrambenih tehnologija na kraju dvadesetog ve$\mathrm{ka}$, a naročito informacionih tehnologija, vođenih postulatima nove filozofije kvaliteta, otvorio je nove mogućnosti u razvoju ratne tehnike.

U osnovi ideje za napretkom stoji zahtev za kvalitet. Obezbeđenje kvaliteta u odbrambenim tehnologijama, koje podržavaju tehničko-tehnološki faktor savremenog rata, postaje primarni interes $u$ daljem napretku moćnih i snažnih zemalja.
Saradnja u oblasti tehničko-tehnološkog razvoja kroz oblike bezbednosnih integracija zemljama u razvoju znatno ce olakšati proces razumevanja, izgradnje i primene sistema menadžmenta kvalitetom u odbrambenim tehnologijama.

Tehnološki, industrijski i ekonomski razvijene zemlje nauku i tehnologiju su stavile u službu jačanja vojnog faktora i njegove uloge u svetu, i tako u jakoj interakciji tehnologije i kvaliteta projektuju, razvijaju, i proizvode savremena vojna tehnička sredstva.

Sistemske odrednice, organizaciona rešenja i formalizovani algoritmi upravljanja kvalitetom u privrednom i tehnološkom potencijalu zemlje delom se uspešno mogu primeniti i u delikatnom području odbrambenih tehnologija.

Pod sistemom kvaliteta podrazumeva se podsistem u poslovnom sistemu koji daje podatak o tome šta sistem sve obuhvata i reguliše. Na pitanje kako sistem funkcioniše, odgovor se dobija kroz dokumenta sistema kvaliteta (poslovnik, planovi kvaliteta, uputstva i instrukcije) i implementaciju dokumenata uvidom u odgovarajuće zapise kvaliteta.

Sistem kvaliteta sadrži: organizacionu strukturu, funkcije, procese, zahteve sistema kvaliteta, dokumenta sistema kvaliteta i metode merenja, praćenja, analize i poboljšanja procesa. Odnosi unutar arhitekture sistema kvaliteta iskazuju se dekompozicionim dijagramima, asocijativnim matricama, tabelama, tehnikama grafičkog prikazivanja i tekstom.

Dekompozicionim dijagramima se, na grafički način, celina posmatra raščlanjeno po svojim sastavnim elementima, 
pri čemu se lako uočavaju međusobne veze, odnosi i nadređenost elemenata $u$ celini.

U opisu elemenata i procesa kvaliteta, kada je to potrebno, treba koristiti kratke, jasne i nedvosmislene formulacije sa odgovarajućim nabrajanjima.

U celini posmatrano, sistem kvaliteta oblikuje, prvenstveno, proizvodni program organizacije i struktura proizvoda, tj. tip unutrašnje organizacije uslovljen osnovnom delatnošću, ciljevima, misijom i politikom. kao:

Sistem kvaliteta može se predstaviti

- raščlanjivanje organizacione strukture;

- uspostavljanje veza između unutrašnje organizacione strukture i poslovnih funkcija;

- raščlanjivanje poslovnih funkcija na potfunkcije;

- identifikacija procesa u okviru poslovnih funkcija;

- uspostavljanje veza između unutrašnje organizacione strukture i procesa;

- uspostavljanje veza između procesa;

- uspostavljanje veza između procesa i zahteva iz standarda kvaliteta;

- utvrđivanje početka i kraja procesa;

- analiza toka procesa (izrada algoritma toka procesa); ciklusu;

- analiza toka procesa po životnom

- dokumentovanje procesa;

- utvrđivanje načina merenja, praćenja, analize i poboljšanja elemenata svakog procesa pojedinačno.

Napredak u razvoju tehnologija, novi dometi i primene rezultata pravovremeno i pravilno definisanih zahteva kva- liteta u tehničko-tehnološkoj strukturi privrede zemlje potvrđuju mesto, ulogu i značaj kvaliteta.

U razmatranju specifičnosti zahteva i potreba učešća kvaliteta u odbrambenim tehnologijama, pored široke primene, standardne forme, zahtevi kvaliteta tržišnih proizvoda nisu mogli u potpunosti odgovoriti potrebama. U kontekstu analize novih izazova u kvalitetu nalazi se potreba da se kvalitet posmatra višemerno i da se iz gledišta višeznačajnog pristupa upravlja kvalitetom.

Kvalitet, kao složen proces, može se smatrati dinamičkim sistemom. Upravljanje kvalitetom zahteva multidisciplinarni pristup, što se može šematski prikazati kao na sl. 1 . Za nove definisane zahteve i postignute uspehe trebalo je kontinuirano unapređivati $\mathrm{i}$ dograđivati zahteve, forme i oblike primene kvaliteta, a parametre kvaliteta pravilno ponderisati i uzročno-posledično formulisati u opštem obrascu logičke postavke procesa istraživanja, razvoja i osvajanja proizvodnje sredstava ratne tehnike.

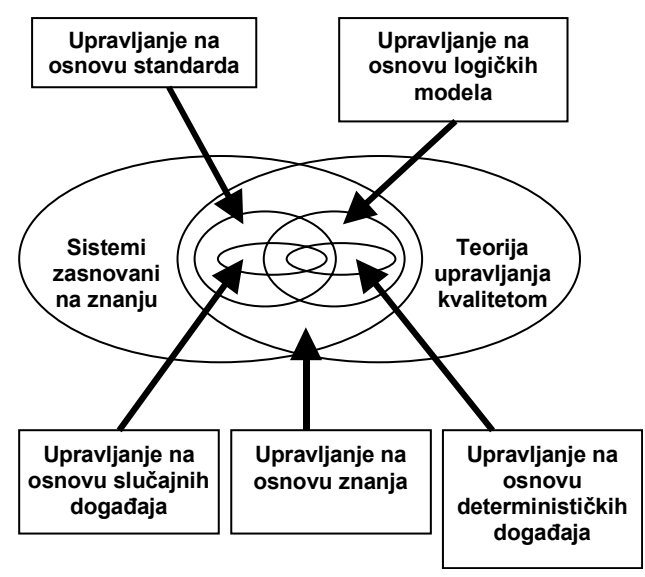

Sl.1 - Šematski prikaz multidisciplinarnog pristupa sistemu menadžmenta kvalitetom 
Osnovne karakteristike savremenih tehničkih sredstava naoružanja i vojne opreme, sa kojima raspolažu razvijene zemlje po njihovim standardima kvaliteta $\mathrm{su}$ : autonomna pokretljivost $\mathrm{u}$ borbenoj upotrebi, zastupljenost visokog stepena automatizacije svih njihovih funkcija i velika potrošnja svih vrsta energije (ubojna sredstva, pogonska sredstva i električna energija) pri izvršenju funkcionalnih zadataka. Njihova konstrukcija je višeznačajna integracija naučno-tehničkih i tehnoloških dostignuća iz više oblasti, a kvalitet upotrebe je rezultat integracija složenih procedura i postupaka implementiranih u sve faze životnog veka sredstva - borbenog sistema.

U tom kontekstu kvalitet se definiše kao mera uspešnosti naoružanja da, pouzdano u svim uslovima determinističkih i stohastičkih okolnosti koje okružuju prostor upotrebe sredstva, izvrši namenski zadatak. Ova činjenica opravdava resurse, snage i sredstva koja se ulažu u istraživanje, razvoj i dogradnju sistema menadžmenta kvalitetom u procesu proizvodnje NVO, a podseća na filozofsku odrednicu da kvalitet mora da prednjači razvoju sredstava, usmerava ga, verifikuje po etapama i fazama i u celini opredeljuje konačan stav o idejnoj zamisli o konceptu razvoja sredstava.

Danas kvalitet u proizvodnji i primeni ratne tehnike predstavlja nadmoć za stranu koja uspeva da ga spozna i primeni i inferiornost za stranu koja ga ne prepoznaje.

Delikatno pitanje je kako male zemlje, koje proizvode naoružanje čije su taktičko-tehničke karakteristike niže od svojstava iste vrste sredstava oružanih snaga ekonomski jakih armija, mogu da obezbede paritet.
Nameće se razmišljanje da je jedino moguće rešenje dodatnim znanjima iz oblasti kvaliteta podići upotrebni nivo sredstva na bazi raspoloživih odbrambenih tehnologija, kako bi se odgovorilo visokoj sofisticiranosti savremenih sredstava koje moćni mogu da razviju i upotrebe. Nove odbrambene tehnologije bez odgovarajućeg sistema kvaliteta koji ih prati i usmerava definiše prednosti i ograničenja, područja primene i zabrane dale bi razorne rezultate.

Proizvodne korporacije koje se do danas nisu transformisale i reorganizovale za tržište doba kvaliteta nemaju budućnost. Zahtevi kvaliteta menjaju tok napretka i transformacije i nameću novu meru u oceni vojne sile.

Osnovni postulati nove filozofije po pitanju kvaliteta su:

- vizionarstvo najvišeg upravljačkog nivoa organizacije;

- prihvatanje holističkog koncepta kvaliteta;

- postavljanje ciljeva kvaliteta i njihova integracija sa poslovnim planovima organizacije;

- obuka i osposobljavanje ljudi za razumevanje i obavljanje različitih zadataka;

- davanje ovlašćenja za donošenje odluka nižim hijerarhijskim nivoima.

Poslednji stavovi predstavljaju implicitno iskazan Taylorov princip razvoja $\mathrm{i}$ usavršavanja radnika, kao i u potpunosti potvrđen Fayolov princip decentralizacije.

Do ovakvog odnosa prema kvalitetu dovelo je uvažavanje činjenice da:

- kvalitet ima mnogo više zajedničkog sa čovekovom prirodom nego što je slučaj sa troškovima i produktivnošću, jer prožima sve životne aktivnosti (Thiel navodi Feurbachove reči ,kvalitet i osećanja su jedno $\mathrm{i}$ isto“); 
- čovek mnogo teže odbija zahtev da unapredi kvalitet, nego zahtev da smanji troškove ili da poveća produktivnost;

- unapređenje kvaliteta predstavlja zadovoljstvo za čoveka, jer se on time samopotvrđuje;

- postoji podjednaka zainteresovanost proizvođača i kupca za kvalitet. Kvalitet proizvoda se sagledava u okviru aktivnosti „savesti“ organizacije (uz ekologiju, bezbednost i dr.), pri čemu su te aktivnosti deo radnih zadataka najvišeg rukovodstva, a kreativno razmišljanje je potporni stub novog koncepta kvaliteta;

- zaključuju se dugoročni ugovori između potrošača i dobavljača, u smislu izbora delova $\mathrm{i}$ isporučilaca, tokova materijala i informacija, sistema obezbeđenja kvaliteta, transporta, itd;

- segmentira se proizvodnja;

- razdvajaju se kapaciteti - modularna organizacija;

- optimiziraju se tokovi;

- izvodi se grupna organizacija: promenljiva veličina serije, najmanje vreme pripreme, prostorna koncentracija opreme sa promenljivim rasporedom, statistička kontrola procesa, integralno upravljanje procesom, princip samokontrole;

- izvodi se integrisani upravljačko-informacioni sistem;

- primenjuju se principi tražnje;

- proizvodnja i nabavka su sa potrebnom pratećom dokumentacijom.

Demingov PDCA ciklus sastoji se od:

- planiranja (utvrđivanja mogućnosti svakog procesa i uspostavljanja statističke kontrole),

- izvršenja (proizvodnje), vodnje),
- delovanja (sinhronizovanja proizvodnje).

Ovaj ciklus čini osnovu integrisanog upravljanja proizvodnjom.

Zahtevi reorganizacije vojske danas, posmatrani iz ugla kvaliteta i u okviru svetskih procesa transformacije armija, trebalo bi da idu u pravcu smanjenja vojnika, manjeg utroška novca i veće efikasnosti upotrebe vojne sile. Dakle, reorganizovana vojska treba da predstavlja efikasnije snage koje svoje resurse (kadrovske i materijalne) koriste drugačije. To je, pre svega, prioritetni zahtev, s obzirom na fundamentalno novo strategijsko okruženje. To je i period kada se definiše novi koncepcijski vojni okvir i kada se postavlja zahtev da se realno odrede vlastite mogućnosti.

Primarno pitanje ovakvih promena postaje tehničko-tehnološka modernizacija koja će omogućiti da se kvantitet nadomesti kvalitetom, u kojem će novi kontekst upotrebe omogućiti novi potencijal.

Dinamika događaja podstiče da se i u oblasti kvaliteta stalno mora iznova stvarati, dograđivati i poboljšavati. Upravljanje kvalitetom kao dinamičkim sistemom, u celini posmatrano, predstavlja spregu - pograničnu oblast tri podsistema iskustvenih saznanja, istraženih procesa i teorije upravljanja, koji imaju interaktivan odnos i međusobno prožimanje nizom aktivnosti, što se šematski može pokazati na slici 2 .

Savremenoj vojsci potrebna su adekvatna sredstva ratne tehnike, veoma precizna i efikasna, koja su rezultat najnovijih dostignuća nauke i tehnike. Uz sve ostale faktore od značaja za vođenje oružane borbe efikasnost vojske je zavisna od efikasnosti tehnike. Vojna sila poistovećuje se sa silom razorne moći oružja. 


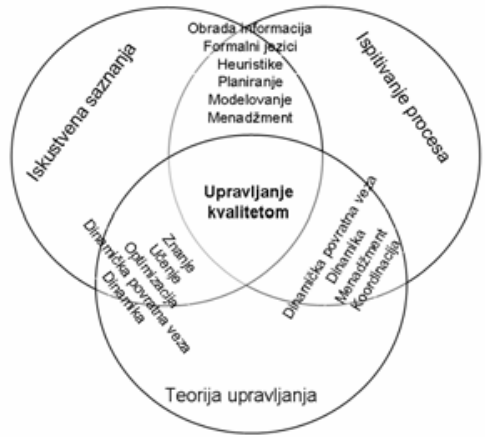

Sl. 2 - Šematski prikaz dinamičke analize sistema menadžmenta kvalitetom

Reorganizacija sistema bezbednosti i njegove vojne sile podrazumeva nameru da se izgrade efektivnije i efikasnije snage pripremljene za budućnost. Suočena sa nizom potencijalnih budućih izazova, a istovremeno i mogućim oblicima integracije i izgradnje kolektivnog sistema bezbednosti, na ravnopravnim partnerskim osnovama, sa gledišta odbrambenih tehnologija, vojska u svojoj reorganizaciji treba da stavi težište na sagledavanju opravdanosti učešća u partnerskim savezima i na tehničko-tehnološku opremljenost, kako bi se kvantitet zamenio kvalitetom.

Cilj modernizacije može se dakle, različito tumačiti, ali ovde se misli, pre svega, na reorganizaciju borbene efikasnosti primenom novih organizacionih $\mathrm{i}$ tehničkih rešenja na već postojeće tehničke sisteme i razvoj i uvođenje u operativnu upotrebu novih tehničkih sredstava. Nezaobilazan sadržaj ovog procesa je strukturalna postavka, procedure i aplikacija sistema kvaliteta, posmatrana i sagledana u svim fazama životnog veka tehničkih sredstava.

\section{Kvalitet sa gledišta logističke organizacije vojske}

Osnovni zadatak i cilj logistike je stvaranje materijalnih, zdrastvenih $i$ infrastrukturnih pretpostavki za izgradnju i održavanje definisane borbene gotovosti vojske. U realizaciji osnovnog zadatka logistika ostvaruje čvrste veze sa nacionalnom ekonomijom i privrednim resursima društva i državne zajednice, čime se, može se reći, formira koncept logističke organizacije vojske implementiran u koncept nacionalne logistike.

U osnovi delatnosti logistike jeste izučavanje i obezbeđenje optimalne podrške u organizacionim i tehničkim sistemima uz razvoj metoda, modela i alata koji će podržavati optimizaciju. Istraživanje, razvoj i proizvodnja NVO prožeti oblastima od više desetina stručnih i naučnih disciplina, sa visokim nivoom zaštite informacija i nedostupnosti u publikacijama usložava proces izučavanja kvaliteta sa gledišta logističkih potreba.

Kvalitet NVO, sa gledišta logističkih potreba, predstavlja doprinos intelektualnog i stručnog rada velikog broja istraživača. Veoma je važno definisati naučno utemeljenje i osnovne principe logističke organizacije Vojske sa gledišta iskustva logističke podrške u uslovima sistema kolektivne bezbednosti. Potrebno je čvrsto i jasno pronaći vezu i oslonac logističkog pristupa i niza naučnih disciplina višeznačajnog karaktera, koje svojom teorijom i praksom daju uporište logistici i podstiču je, čije naučne principe, metode i aksiome logistika potpuno koristi u tumačenju i verifikaciji tačnosti rezultata istraživanja u odnosu odbrambene tehnologije - kvalitet - logistika. 
Ocena valjanosti definisanog modela tehničkog rešenja i menadžmenta kvalitetom, sa gledišta logističke podrške, naglašava primarni uticaj kriterijuma operativnosti i efikasnosti, koji karakterišu predloženu organizaciju.

Težišno je razmatranje tehničke logistike, kao podsistema logistike, koja obezbeđuje podršku tehničkih sistema sa nizom svojih karakteristika. Zbog složenosti problematike istraživanja i razvoja naoružanja, neophodni su najobrazovaniji stručnjaci i vrhunske tehnologije ne samo $\mathrm{u}$ oblasti tehničkih nauka, nego i mnogih drugih. Razvoj je karakterističan, pored ostalog, i po tome što su informacije $u$ početnim aktivnostima manje dostupne, dok se, kasnije, najznačajnija dostignuća ostvarena kroz ove tehnologije, tehnološka rešenja i nova saznanja koriste $\mathrm{u}$ privredi i predstavljaju motornu snagu njenog daljeg razvoja.

Mora se analizirati međuzavisnost parametara pouzdanosti, pogodnosti za održavanje, raspoloživosti i logističke podrške i najpovoljniji odnos tih parametara u ukupnim troškovima održavanja tehničkog sistema. Težišno pitanje te međuzavisnosti i uzročno-posledične povezanosti je kvalitet. Sa gledišta kvaliteta nužno je razmatrati sveukupnost tehničke logistike, korektivnih akcija, sprečavanje otkaza i definisanje sposobnosti tehničkog sistema da funkcioniše alternativno $\mathrm{u}$ uslovima neispravnosti pojedinih komponenata ili brojnih drugih determinističkih ili stohastičkih ograničenja okruženja u kojem se sistem upotrebljava.

Posmatrajući sistem odbrane po podsistemima, posebno sa aspekta logistike, može se uočiti izražena uloga siste- ma menadžmenta kvalitetom (QMS), odnosno fokusiranje na taj (pod)sistem, s obzirom na njegovu uređenost određenim standardima i, u skladu s tim, definisana pravila koja se odnose na većinu procesa i aktivnosti u sistemu odbrane. Ne upuštajući se u objašnjenje neophodnosti uspostavljanja i opravdanosti velikih očekivanja od QMS, valja istaći da on manje ili više zadire $u$ druge podsisteme sistema odbrane.

Uspostavljanje, funkcionisanje i razvoj QMS podrazumeva niz pravovremenih i kvalitetnih informacija. Istovremeno, sistem menadžmenta kvalitetom mora imati izgrađene mehanizme definisanja sopstvenih pravila, kao i nadzora nad primenom tih pravila, što podrazumeva postojanje odgovarajućeg informacionog sistema.

\section{Povezivanje logistike i QMS}

Sistem menadžmenta kvalitetom, sa gledišta logistike, ima pretenzije da, odgovarajućim dokumentima i pravilima, uredi određene logističke procese u sistemu odbrane. Iako je, pri tome, težište na kvalitetu (odabranih - logističkih) procesa i njihovih proizvoda, opravdano je da se tim uređenjem obuhvate i procesi zahtevi u pogledu obezbeđenja potrebnih tehnoloških unapređenja QMS u celom sistemu odbrane.

Procesi logističke podrške imaju za cilj stvaranje proizvoda kojima se zadovoljavaju kroz kvalitet definisani zahtevi odbrane. Pri tome, da bi se obezbedilo zadovoljavajuće upravljanje procesima logistike, nužno je da se poštuju pravila definisana sistemom kvaliteta. Zahtevi u 
pogledu standardizovanog uređenja procesa logistike, kao i kvaliteta proizvoda, nameću prirodnu spregu logistike i QMS.

Logistički koncept organizacije Vojske, po pitanju kvaliteta NVO, dao je novu meru i novi izazov. Potrebno je tragati za odgovorom kako posmatrati i definisati kvalitet ratne tehnike u uslovima kada proizvodnja naoružanja i vojne opreme nije više privilegija samo jednog dela privrednih subjekata, do sada namenske industrije, već državne zajednice u najširem smislu. Kako postaviti algoritam procesnog pristupa definisanja zahteva, procedura, sistema kontrole kvaliteta, kontrolnih subjekata, zakonskih obaveza i mesta i uloge buduće agencije za kvalitet u uslovima dominantnog uticaja nacionalne nad vojnom logistikom i na putu tranzicija i predstojećih bezbednosnih integracija.

Sve to nameće obavezu da kontrola kvaliteta tehničkih sredstava bezbednosnog sektora traži nove forme organizacije, nove oblike delovanja, efikasne i ekonomskim kategorijama opravdane kriterijume ocene i procedure verifikacije kvaliteta.

\section{Zaključak}

Osnovni cilj ovog rada je da ukaže na neophodnost uspostavljanja čvrste veze između sistema menadžmenta kvalitetom i procesa tehnološkog lanca razvoja i proizvodnje NVO sa gledišta logističkih potreba. Bez te veze, odnosno njenog željenog funkcionisanja, QMS ima male šanse na uspeh.

Tekuće i predstojeće reforme u sistemu bezbednosti i nova uloga i zadaci vojske u integrativnim procesima, pitanju kvaliteta u logističkoj podršci u celini, a proizvodnji naoružanja i vojne opreme posebno, nametnuli su potrebu nove arhitekture sistema kvaliteta i njegove aplikacije u svim aktivnostima, procesima $i$ postupcima.

Sistem menadžmenta kvalitetom višekriterijumski se analizira i optimizira. Standardizovane forme, algoritamski definisane procedure i numeričke ocene valjanosti, formulisani metodama matematičke statistike, osnovni su činioci organizacije nove arhitekture ovog sistema.

Sistem menadžmenta kvalitetom u naoružanju i vojnoj opremi razvijenih zemalja i velikih armija nam je poznat. Suštinsko pitanje je kako izvršiti implementaciju takvog sistema sa ograničenim kadrovskim, tehnološkim i finansijskim mogućnostima.

Provera i ocena ovog sistema dobija novu meru, mesto i ulogu i predstavlja polaznu i završnu aktivnost u algoritmu izvršavanja složenih zadataka organizacije logistike, logističkih funkcija i zadataka u podršci vojske. Kvalitet i njegova primena u konceptu logističke podrške vojske dali su veći značaj, novo mesto i ulogu materijalno-tehničkom faktoru rata $\mathrm{u}$ analizi strategijskih pitanja sistema bezbednosti.

\section{Literatura:}

[1] Fokusirana logistika (prevod smernica fokusirane logistike) OPU SP GŠ VJ, 1998.

[2] Koptjuv, V. A.; Matrosov, V. M.; Levasov, V. K.: Novaja paradigma razvitija Rossii, Rasijskaja akademija nauk, Moskva 1.

[3] Tomanović, R.; Nikolić, M.: Komparativna analiza pozadinskog obezbeđenja Vojske Jugoslavije i logističke podrške stranih oružanih snaga, studija, SP GŠ VJ, 1998.

[4] Milinović, M.; Đedović, B.: Vojnoindustrijska i civilna saradnja u naučnoj i tehnološkoj i obrazovnoj oblasti kao faktor izbora savremene koncepcije globalne i lokalne odbrane, SIMVON 2001. 
[5] Hedrih-Stevanović, K.; Đedović, B.: Modeliranje strateškog naoružavanja u višepolarnom svetu, Vojno delo, No 4-5, 2000.

[6] Milinović, M.; Đedović, B.: Uticaj savremenog tehnološkog razvoja NVO na vojne strategije i ukupne integrativne procese manjih zemalja i armija, SIMVON 2001.

[7] Milinović, M.; Đedović, B.: Jedan pogled na pravce razvoja tehničko-tehnološkog faktora i njegovih naučno-proizvodnih implikacija u duhu reorganizovanih potreba zemlje, SIMOPIS 2001.

[8] Milinović, M.; Đedović B.: Činioci tehničko-tehnološkog razvoja u funkciji stabilnog razvoja zemlje, Vojno delo, No 6, 2001.
[9] Đedović, B.; Hedrih - Stevanović, K.; Milinović, M.: Mogućnosti primene matematičkih modela i metoda istraživanja u funkciji naučne izgrađenosti vojne strategije, SIMVON 2001.

[10] CR Ministry of Defense, Logistic support, Beograd, July 8,2003 , The brifing,

[11] Ministarstvo odbrane Mađarske, Logistička podrška, 2003, prevod,

[12] Vasilev, S. N.; Žerlov, A. K.; Fedosov, E. A.; Fedunov, B E.: Intelektnoe upravlenie dinamičeskimi sistemami, Moskva, Fizmatlit, 2000 